Nitin Joseph', Shreeshaina², Shivani Bhat Loliem², Vinod Kumar Gundi², Mrudula Bhargav Herambapura Subramanya ${ }^{2}$, Shreyashree Belthur Shashidhar ${ }^{2}$

'Department of Community Medicine, Kasturba Medical College, Mangalore, Manipal Academy of Higher Education, Manipal, India

${ }^{2}$ MBBS student, Kasturba Medical College, Mangalore, Manipal Academy of Higher Education, Manipal, India

\title{
An assessment of risks associated with obstructive sleep apnea and its relationship with adverse health outcomes among pregnant women. A multi-hospital based study
}

\begin{abstract}
Introduction: Physiological changes in pregnancy increase the vulnerability of antenatal women to develop obstructive sleep apnoea (OSA). It is a known cause of several adverse health outcomes in pregnancy.

Objectives: To assess the risk status of OSA in pregnant women and to study its association with adverse maternal outcomes, fatigability, and daytime sleepiness.

Material and methods: Pregnant women were interviewed to assess for the risk of OSA, fatigability, and daytime sleepiness. STOP BANG, the fatigue severity scale, and the Epworth sleepiness scale were used to assess these parameters.

Results: The mean age of the 214 participants was $27.2 \pm 4.7$ years. 7 (3.3\%) participants had a history of snoring louder than the volume of normal talking, or of being loud enough to be heard past closed doors. A moderate risk status of OSA was present among $3(1.4 \%)$ participants. $45(21.0 \%)$ pregnancies were high risk in nature. The risk status of OSA was associated with a high risk status of pregnancies among the participants $(p=0.0088) .41(19.2 \%)$ participants had a history of significant fatigue over the previous week of the study. 7 (3.3\%) participants reported mild to severe excessive daytime sleepiness. A history of snoring loudly $(p=0.0179)$ and OSA risk status $(p=0.0027)$ was associated with excessive daytime sleepiness.

Conclusions: A risk status for OSA was associated with a high risk pregnancy status and excessive daytime sleepiness among pregnant women in the current setting. Therefore, pregnant women with these conditions need to be evaluated for OSA. They also need to be suitably managed to ensure the healthy well-being of the mother and the baby.
\end{abstract}

Key words: pregnant women, obstructive sleep apnea, fatigue, daytime sleepiness

Adv Respir Med. 2020; 88: 327-334

\section{Introduction}

Pregnancy is a state associated with a number of physiological changes in the body. High levels of progesterone and estrogen during pregnancy cause fluid retention leading to swelling around the neck, mucus membranes, and nasal passages. These changes result in narrowing of the oropharyngeal diameter and increased upper airway resistance leading to the occurrence of snoring [1]. As many as $25 \%$ of pregnant women have been found to be first time snorers during the gestational period [1]. Heavy snoring accompanied by pauses in breathing lead to a state of obstructive sleep apnea (OSA) [1]. The state of reduced oxygenation during each episode of OSA can end with disastrous consequences both in the antenatal and in the intranatal period [2]. Prior studies have observed OSA complicating pregnancy and resulting in an increased risk of intensive care admission as well as an increased duration of time spent in the hospital [3].

Although OSA is a common complication in pregnancy, it unfortunately remains underdiagnosed due to reasons such as variable clinical presentations [4] and poor validity of certain questionnaire-based tools [5]. Overnight polysomnogram, which is the gold standard for its diagnosis, is an

Address for correspondence: Nitin Joseph, Department of Community Medicine, Kasturba Medical College, Mangalore, India; e-mail: drnitinjoseph@gmail.com DOI: $10.5603 /$ ARM.a2020.0104

Received: 09.03.2020

Copyright (C) 2020 PTChP

ISSN 2451-4934 
expensive, time-consuming, and uncomfortable procedure which is not practical for application [6].

Surveys have reported that $90 \%$ of pregnant patients with OSA were unaware of OSA and its consequences [7]. Doctors may also misinterpret the excessive daytime sleepiness complaints among antenatal women as a normal symptom of pregnancy. This results in a further delay in its identification and management [8].

This study was therefore done to study the risk status of OSA among pregnant women at various tertiary care centres in an urban setting. Its association with adverse maternal outcomes, fatigability, and daytime sleepiness were also evaluated in this study.

\section{Material and methods}

This cross-sectional study was conducted among pregnant women, both admitted and those seeking outpatient services, at a private and a government tertiary care hospital in Mangalore, India. Ethical clearance was approved by the Institutional Ethics Committee. The reference number was IECKMCMLR/023/2019. Permission was granted by the medical superintendent of the respective hospitals. The study was conducted in the month of February 2019.

Consent was given in writing after clarifying the procedure and purpose of the study to each participant.

Assuming that 31.9\% [9] of pregnant women are at a greater risk for developing OSA, the sample size was calculated as 214 at $95 \%$ confidence intervals and $80 \%$ power using the formula $\mathrm{n}=4 \mathrm{pq} / \mathrm{d}^{2}$.

All participants were examined only once as a part of this study. They were enrolled using the convenience sampling method. Participants aged 18 years and above were included whereas those who refused to give consent for participation were excluded from this study. They were then interviewed using a structured interview schedule. The risk status for developing OSA was assessed using the STOP BANG questionnaire. It has eight items with responses for each in a "yes" and "no" format. The participant was categorized as having either a low, moderate, or high risk of OSA if they answered "yes" to $<3,3-4, \geq 5$ items respectively. This tool has been validated to identify OSA in pregnancy and has been found to have the highest specificity among the various questionnaire-based OSA screening tools [10].

The current level of fatigue among participants was assessed using the fatigue severity scale (FSS) which consists of nine items. The responses to each item were "strongly disagree", "moderately disagree", "slightly disagree”, "neutral”, "slightly agree", "moderately agree", and "strongly agree" in a Likert scale with scores ranging from 1 to 7 respectively. A cumulative score of $\geq 36$ was indicative of a significant level of fatigue among the participants.

Desire to sleep while engaging in different activities during the daytime in recent times was assessed using the Epworth sleepiness scale (ESS). The responses to the eight items in this scale were "would never nap", "slight chance of napping", "moderate chance of napping" and "high chance of napping", scored from 0 to 3 respectively. An ESS score over 10 was indicative of excess daytime sleepiness.

The internal consistency of the STOP BANG questionnaire, FSS and ESS used in this study had the Cronbach's alpha value of $0.724,0.878$ and 0.693 respectively, indicating good reliability.

Demographic details (age, occupation, education, and place of residence), obstetric details (obstetric score and gestational age), and the presence of risk factors (co-morbidities, history of tobacco usage, long standing medication history, family history of snoring, and known status of OSA) were enquired about among the respondents.

In addition, height, weight, neck circumference, and blood pressure were measured among all participants using instruments like stadiometers, measuring tapes, weighing scales and mercury sphygmomanometers as per standard guidelines.

Pre-pregnancy weight, recent haemoglobin values, and recent fasting blood sugar (FBS) values were noted from the antenatal records of the participants. BMI status was assessed using the Asian classification. Participants with haemoglobin values $<11 \mathrm{~g} / \mathrm{dL}$ were categorized as anaemic and those with FBS $\geq 95 \mathrm{mg} / \mathrm{dL}$ of blood were interpreted as having increased blood sugar levels.

The interview schedule was content validated and was also language validated in the local language "Kannada" with the help of experts. The schedule was then pilot tested among 10 antenatal women who were not part of the main study.

IBM SPSS for Windows version 25.0, Armonk, New York was used for data entry and analysis. The Chi-square test and Fisher's exact test were used to test association. $\mathrm{p}<0.05$ was considered a significant association.

\section{Results}

Out of the 214 pregnant women, 138 (64.5\%) were from the government hospital and 76 (35.5\%) 
Table 1. Socio-demographic distribution of pregnant women

\begin{tabular}{|c|c|c|}
\hline Characteristics & Number & Percentage \\
\hline \multicolumn{3}{|l|}{ Age group (years) } \\
\hline 18-20 & 20 & 9.4 \\
\hline $21-25$ & 54 & 25.2 \\
\hline $26-30$ & 88 & 41.1 \\
\hline $31-35$ & 44 & 20.6 \\
\hline $36-38$ & 8 & 3.7 \\
\hline \multicolumn{3}{|l|}{ Educational status } \\
\hline Graduate/postgraduate & 24 & 11.2 \\
\hline Pre-university course/ diploma & 48 & 22.4 \\
\hline High school & 71 & 33.2 \\
\hline Middle school & 34 & 15.9 \\
\hline Primary school & 17 & 7.9 \\
\hline Illiterate & 20 & 9.4 \\
\hline \multicolumn{3}{|l|}{ Occupational status } \\
\hline Housewives & 174 & 81.3 \\
\hline Semi-professionals & 15 & 7.0 \\
\hline Semi-skilled workers & 12 & 5.6 \\
\hline Unskilled workers & 13 & 6.1 \\
\hline \multicolumn{3}{|l|}{ Place of residence } \\
\hline Urban & 169 & 79.0 \\
\hline Rural & 45 & 21.0 \\
\hline Total & 214 & 100.0 \\
\hline
\end{tabular}

were from the private hospital. 27 (12.6\%) were admitted while 187 (87.4\%) had come for antenatal check-ups on an outpatient basis at these hospitals.

Reasons for admission included pregnancy induced hypertension (PIH) among 7 patients, abdominal pain and bleeding among 7 , safe confinement among 2, oligohydramnios among 2, gestational diabetes mellitus (GDM) among 2, hypotension in 1 , vomiting and dysentery in 1 , renal calculi in 1, anaemia in 1, placenta praevia in 1 , polyhydramnios in 1 , and fetal microsomia in 1 .

The mean age of the participants was $27.2 \pm$ 4.7 years. The majority of participants were educated up to high school level [71 (33.2\%)], were housewives [174 (81.3\%)], and were from urban areas [169 (79\%)] (Table 1).

The majority of pregnant women were in the third trimester [144 (67.3\%)]. A past history of abortion was reported among 27 (12.6\%) participants (Table 2). Out of the 214 participants, a history of a single episode of abortion was present among 23 (10.7\%), two episodes among
Table 2. Pregnancy-related characteristics among participants

\begin{tabular}{|c|c|c|}
\hline Characteristics & Number & Percentage \\
\hline \multicolumn{3}{|l|}{ Trimester } \\
\hline First & 13 & 6.1 \\
\hline Second & 57 & 26.6 \\
\hline Third & 144 & 67.3 \\
\hline \multicolumn{3}{|l|}{ Gravida } \\
\hline Prima & 118 & 55.1 \\
\hline Second & 63 & 29.4 \\
\hline Third & 25 & 11.7 \\
\hline Fourth & 7 & 3.3 \\
\hline Seventh & 1 & 0.5 \\
\hline \multicolumn{3}{|l|}{ Parity } \\
\hline Nulliparous & 125 & 58.4 \\
\hline First & 60 & 28.0 \\
\hline Second & 23 & 10.8 \\
\hline Three & 6 & 2.8 \\
\hline \multicolumn{3}{|l|}{ Number of children } \\
\hline None & 129 & 60.3 \\
\hline One & 63 & 29.5 \\
\hline Two & 17 & 7.9 \\
\hline Three & 5 & 2.3 \\
\hline Past history of abortion & 27 & 12.6 \\
\hline High risk status of pregnancy & 45 & 21.0 \\
\hline $\begin{array}{l}\text { Recent haemoglobin value } \\
<11 \mathrm{~g} / \mathrm{dL}\end{array}$ & 43 & 20.1 \\
\hline Total & 214 & 100.0 \\
\hline
\end{tabular}

$2(0.9 \%)$, and three and four episodes in $1(0.5 \%)$ participant each. The current BMI status was underweight among 22 (10.3\%), normal among 82 (38.3\%), overweight among 52 (24.3\%), and obese among $58(27.1 \%)$ participants. A current body mass index (BMI) more than $35 \mathrm{~kg} / \mathrm{m}^{2}$ was present in only one participant.

$45(21.0 \%)$ of the total pregnancies were high risk in nature. The mean age of these women was $28.5 \pm 4.5$ years. Six (13.3\%) were illiterates, $4(8.9 \%)$ were educated up to primary school, 7 (15.6\%) up to middle school, 10 (22.2\%) up to high school, $12(26.7 \%)$ completed a pre-university course/diploma, and 6 (13.3\%) of them were educated at the undergraduate/postgraduate level. Six (13.3\%) of them were coolie workers, $4(8.9 \%)$ were beedi rollers, and the rest were house wives. Thirty two (71.1\%) of them were from rural areas. Twenty nine (64.5\%) were pri- 
Table 3. Association between risk factors and OSA risk status among the participants

\begin{tabular}{|c|c|c|c|}
\hline \multirow{2}{*}{$\begin{array}{l}\text { Characteristics } \\
\text { Trimester }\end{array}$} & \multicolumn{2}{|c|}{ OSA risk status } & \multirow[b]{2}{*}{ Total } \\
\hline & Moderate risk (\%) & Low risk (\%) & \\
\hline First & $0(0)$ & $13(100)$ & 13 \\
\hline Second & $1(1.8)$ & $56(98.2)$ & 57 \\
\hline \multirow[t]{2}{*}{ Third } & $2(1.4)$ & $142(98.6)$ & 144 \\
\hline & & & $\mathrm{X} 2=0.236, \mathrm{p}=0.889$ \\
\hline \multicolumn{4}{|l|}{ Age group (years) } \\
\hline$\leq 30$ & $1(0.6)$ & $161(99.4)$ & 162 \\
\hline \multirow[t]{2}{*}{$>30$} & $2(3.9)$ & $50(96.1)$ & 52 \\
\hline & & & $p=0.1471$ \\
\hline Total & 3 & 211 & 214 \\
\hline \multicolumn{4}{|c|}{ BMI status before pregnancy } \\
\hline Underweight/ normal & $2(1.8)$ & $111(98.2)$ & 113 \\
\hline \multirow[t]{2}{*}{ Overweight/obese } & $1(2.7)$ & $36(97.3)$ & 37 \\
\hline & & & $p=1$ \\
\hline Total & 3 & 147 & 150 \\
\hline \multicolumn{4}{|c|}{$\begin{array}{l}\text { Weight gain among women coming for ANC } \\
\text { visit between } 32 \text { to } 33 \text { weeks in comparison to } \\
\text { their pre-pregnancy weight }\end{array}$} \\
\hline$<11$ kilograms & $0(0)$ & $11(100)$ & 11 \\
\hline \multirow[t]{2}{*}{$\geq 11$ kilograms } & $1(50)$ & $1(50)$ & 2 \\
\hline & & & $p=0.1538$ \\
\hline Total & 1 & 12 & 13 \\
\hline
\end{tabular}

ANC — antenatal care; BMI — body mass index; OSA — obstructive sleep apnoea

migravida, 13 (28.9\%) were of second gravida, $2(4.4 \%)$ were of third gravida, and $1(2.2 \%)$ was of fourth gravida. Four $(8.9 \%)$ of them were underweight, 17 (37.8\%) were normal, 9 (20\%) were overweight and 15 (33.3\%) were obese as per their BMI status. The reasons for high risk pregnancies were PIH among 15, hypothyroidism among 6, GDM among 5, Rh negative status among 3 , abdominal pain and bleeding among 2 , hypotension among 2, oligohydramnios among 2 , polyhydramnios in 1 , threatened abortion in 1 , fibroid in 1, ovarian cyst in 1, GDM and PIH in 1 , GDM and asthma in 1, psoriasis in 1, placenta praevia in 1, pre-eclampsia in 1, and hyperthyroidism and PIH in 1 participant.

A history of the use of long-standing medications prior to pregnancy was present among 8 patients. The medications used by them were labetalol among 3, metformin among 3 , and iron tablets among 2 patients. Current blood pressure readings were raised among $5(2.3 \%)$, the most recent FBS levels were raised among 2 (0.9\%) and the glucose challenge test result was on the higher side in 1 participant.
Seven (3.3\%) participants had a history of snoring louder than the volume of normal talking or being loud enough to be heard through closed doors. Only 1 participant had a positive family history of snoring.

A history of snoring loudly was reported among 3 (6.7\%) of the 45 participants with a high risk pregnancy status in comparison to 4 (2.4\%) out of 169 participants with normal pregnancy status $(\mathrm{p}=0.163)$. There was no association of having a history of snoring loudly as a result of gravida status $>2(\mathrm{p}=1)$, multigravida status ( $\mathrm{p}$ $=1)$, parity $>2(\mathrm{p}=1)$, number of living children $>2(p=1)$, past history of abortion $(p=0.5996)$, trimester status $(p=0.531)$, being a housewife by occupation $(p=1)$, being illiterate $(p=0.502)$, residential status $(\mathrm{p}=0.349)$, recent FBS values $(\mathrm{p}=1)$, haemoglobin $<11 \mathrm{~g} / \mathrm{dL}(\mathrm{p}=0.34)$, a history of taking long standing medications ( $p$ $=0.237)$, family history of snoring $(p=1)$, age $>$ 30 years $(\mathrm{p}=0.3645)$, pre pregnancy BMI status ( $p=0.6367)$, current BMI status ( $p=0.715)$, and weight gain among women coming for ANC visit between 32 and 33 weeks $(n=13)$ in comparison 
to their pre-pregnancy weight $(\mathrm{p}=0.2949)$ among the participants.

Five $(2.3 \%)$ participants had a positive history for someone having observed them stop breathing during sleep.

Moderate risk status for the development of OSA were present among 3 (1.4\%) out of the total 214 participants.

There was no association between gravida status $>2(p=0.3965)$, multigravida status ( $p$ $=0.589)$, parity $>2(\mathrm{p}=1)$, number of living children $>2(p=1)$, history of abortion $(p=1)$, third trimester status $(\mathrm{p}=1)$, being a housewife by occupation $(p=0.4642)$, educational status $(p=1)$, place of residence $(p=1)$, family history of snoring $(\mathrm{p}=1)$, haemoglobin $<11 \mathrm{~g} / \mathrm{dL}(\mathrm{p}=$ 0.571 ), history of taking long standing medications $(p=0.108)$, current BMI status $(p=1)$, weight gain among women coming for ANC visit between 22 to 23 weeks in comparison to their pre-pregnancy weight $(n=3 ; p=1)$, weight gain among women coming for ANC visit between 39 to 40 weeks in comparison to their pre-pregnancy weight $(\mathrm{n}=9 ; \mathrm{p}=0.4444)$ and OSA risk status.

A moderate risk status for OSA was present among $2(3.9 \%)$ out of 52 women aged more than 30 years in comparison to $1(0.6 \%)$ out of 162 women aged 30 years or below $(p=0.1471)$. (Table 3)

Risk status for OSA was associated with a high risk status of pregnancy among the participants ( $\mathrm{p}=0.0088$ ) (Table 4).

Forty one (19.2\%) participants were found to have a history of significant fatigue over the previous week of the study. Lower normal daytime sleepiness was present among 177 (82.7\%), higher normal daytime sleepiness among 30 (14\%), mild excessive daytime sleepiness among 3 (1.4\%), moderate excessive daytime sleepiness among 3 (1.4\%), and severe excessive daytime sleepiness in $1(0.5 \%)$ participant in recent times.

A history of snoring loudly $(\mathrm{p}=0.0179)$ and OSA risk status $(\mathrm{p}=0.0027)$ was associated with excessive daytime sleepiness (Table 4).

\section{Discussion}

Early identification of OSA among pregnant women is essential for both maternal and fetal well-being.

A history of snoring loudly was present among 3.3\% participants which was less than the findings of previous studies [21.2\% and $35.3 \%$ $(11,12)]$. The tendency to snore occurs as a result of the normal physiological changes during pregnancy which lead to narrowing of upper airways. A history of snoring and frequent snoring ( $\geq 3$ nights/week) among pregnant women have also been linked to the surge of estrogen and progesterone levels during the antenatal period [13].

In the current study, $1.4 \%$ of the participants were found to have a greater risk for developing OSA which was again less than $13.4 \%$ [14], $18.4 \%$ [15], 26.4\% [9], 26.7\% [16] and 30.9\% [17] reported in previous studies. The trimester wide distribution of greater risk status for OSA was none in the first, $1.8 \%$ in the second, and $1.4 \%$ in the third trimester among participants in this study. In previous studies, the risk of OSA in the first trimester was reported as 10.5\% [18], 10.7\% [2], and $30.4 \%$ [9]; in the second trimester $29 \%$ [19] and $33.3 \%$ [9]; in the third trimester $24.1 \%$ [2], 26.7\% [18], 32\% [9], and 34.7\% [20] of all participants. The risk of OSA was therefore low in particular trimesters of pregnancy in this study compared to the results of other authors.

However, it is notable that the risk of developing OSA was observed to increase in the second and third trimesters as compared to the first trimester of pregnancy in this study. This can be explained due to the fact that the enlarging uterus elevates the diaphragm and alters respiration. These alterations during sleep increase the risk of upper airway collapse, and for OSA, as the pregnancy progresses. An increase in the levels of estrogen and progesterone as the pregnancy advances is also responsible. An increase in estrogen concentration increases mucosal edema and progesterone increases the respiratory centre's sensitivity to carbon dioxide and destabilizes the respiratory control mechanism [21]. Therefore, it is important to screen for OSA and monitor for its development during every trimester as the pregnancy advances. It has been recommended to screen for OSA between 12 and 18 weeks to allow adequate time for its evaluation and early management [22].

In a study done in Peru, overweight and obese pregnant women were more likely to report a history of snoring [23]. Snoring has been found to be a risk factor for PIH, pre-eclampsia and GDM [24]. However, these were different from our observations because no such association was seen.

No specific risk factors were associated with OSA risk status in this study. This was again different from findings of previous studies where age [2, $14,18]$, tongue enlargement [2], pre-pregnancy BMI [9], first trimester BMI [18], current BMI [2, 9, 14, 13] and weight gain during pregnancy [9] were reported as potential risk factors for developing OSA. 
Table 4. Association between a history of snoring loudly and OSA risk status with a high risk status of pregnancy, fatigue, and excessive daytime sleepiness among participants

\begin{tabular}{|c|c|c|c|}
\hline \multirow[b]{2}{*}{ History of snoring loudly } & \multicolumn{2}{|c|}{ Fatigue status } & \multirow[b]{2}{*}{ Total } \\
\hline & Present & Absent & \\
\hline Present & $2(28.6)$ & $5(71.4)$ & 7 \\
\hline \multirow[t]{2}{*}{ Absent } & $39(18.8)$ & $168(81.2)$ & 207 \\
\hline & & & $p=0.621$ \\
\hline \multirow[t]{2}{*}{ Total } & 41 & 173 & 214 \\
\hline & \multicolumn{2}{|c|}{ Daytime sleepiness status } & \\
\hline History of snoring loudly & Excessive & Normal & Total \\
\hline Present & $2(28.6)$ & $5(71.4)$ & 7 \\
\hline \multirow[t]{2}{*}{ Absent } & $5(2.4)$ & $202(97.6)$ & 207 \\
\hline & & & $p=0.0179$ \\
\hline \multirow[t]{2}{*}{ Total } & 7 & 207 & 214 \\
\hline & \multicolumn{2}{|c|}{ Type of pregnancy } & \\
\hline History of snoring loudly & High risk & Normal & \\
\hline Present & $3(42.9)$ & $4(57.1)$ & 7 \\
\hline \multirow[t]{2}{*}{ Absent } & $42(20.3)$ & $165(79.7)$ & 207 \\
\hline & & & $p=0.163$ \\
\hline \multirow[t]{2}{*}{ Total } & 45 & 169 & 214 \\
\hline & \multicolumn{2}{|c|}{ PIH/Pre-Eclampsia status } & \\
\hline History of snoring loudly & & Absent & \\
\hline Present & & $6(85.7)$ & 7 \\
\hline \multirow[t]{2}{*}{ Absent } & & $190(91.8)$ & 207 \\
\hline & & & $p=0.464$ \\
\hline \multirow[t]{2}{*}{ Total } & & 196 & 214 \\
\hline & \multicolumn{2}{|c|}{ Fatigue status } & \\
\hline OSA risk status & Present & Absent & Total \\
\hline Moderate risk & $2(66.7)$ & $1(33.3)$ & 3 \\
\hline \multirow[t]{2}{*}{ Low risk } & $39(18.5)$ & $172(81.5)$ & 211 \\
\hline & & & $p=0.095$ \\
\hline \multirow[t]{2}{*}{ Total } & 41 & 173 & 214 \\
\hline & \multicolumn{2}{|c|}{ Daytime sleepiness status } & \\
\hline OSA risk status & Excessive & Normal & Total \\
\hline Moderate risk & $2(66.7)$ & $1(33.3)$ & 3 \\
\hline \multirow[t]{2}{*}{ Low risk } & $5(2.4)$ & $206(97.6)$ & 211 \\
\hline & & & $p=0.0027$ \\
\hline \multirow[t]{2}{*}{ Total } & 7 & 207 & 214 \\
\hline & & lancy & \\
\hline OSA risk status & High risk & Normal & \\
\hline Moderate risk & $3(100)$ & $0(0)$ & 3 \\
\hline Low risk & $42(19.9)$ & $169(80.1)$ & 211 \\
\hline & & & $p=0.0088$ \\
\hline Total & 45 & 169 & 214 \\
\hline & & ia status & \\
\hline OSA risk status & & Absent & \\
\hline Moderate risk & & $2(66.7)$ & 3 \\
\hline Low risk & & $194(91.9)$ & 211 \\
\hline & & & $p=0.233$ \\
\hline Total & & 196 & 214 \\
\hline & & & \\
\hline OSA risk status & & Absent & \\
\hline Moderate risk & & $2(66.7)$ & 3 \\
\hline Low risk & & $205(97.2)$ & 211 \\
\hline & & & $p=0.0954$ \\
\hline Total & & 207 & 214 \\
\hline
\end{tabular}


Although OSA risk status was associated with a high risk status of pregnancy, it was not specifically associated with either hypertensive disorders or GDM among participants in this study. In other studies, OSA in pregnancy was associated with PIH $[14,24]$, preeclampsia [15, $24]$ and GDM [14, 24]. Various hypertensive disorders in pregnancy have been suggested to result from endothelial dysfunction as a consequence of OSA related intermittent hypoxemia [25]. Frequent arousals from sleep among OSA patients lead to a decrease in slow wave sleep. This causes sympathetic activation which disrupts the hypothalamic-pituitary-adrenal axis. Altered sleep also causes an alteration in cortisol synthesis and release. These mechanism induce insulin resistance and alter glucose homeostasis [26, 27]. Periodic hypoxia in OSA affects beta cell activity of the pancreas [28].

Pregnant women are therefore advised to sleep in a lateral position which keeps airways open and thereby minimizes the risk of hypoxia induced by OSA [25]. On top of this, continuous airway positive pressure (CPAP), if initiated early in pregnancy even in those with history of chronic snoring, would be beneficial in blood pressure control [4]. Tolerance to nasal CPAP has been found to be good during pregnancy without reports of any adverse effects [29].

There was no association between OSA risk status and fatigability among pregnant women in this study.

However, the present study found that a history of snoring loudly and OSA risk status were associated with excessive daytime sleepiness among pregnant women. This was in contrast to the findings of previous studies done in the USA [18] and in Thailand [9] where no such association was reported. Medical practitioners and patients themselves end up mistaking excessive daytime sleepiness as usual symptoms in pregnancy. This may further delay the diagnosis and management of OSA which needs to be taken care of [8]. Health care providers need to further take up the responsibility of bringing up the awareness about OSA and its consequences among pregnant women. This is important as pregnancy may be the only occasion during which the woman might seek medical attention.

\section{Conclusions}

OSA risk status was associated with a high risk pregnancy status and excessive daytime sleepiness among pregnant women in the current setting.
Therefore, pregnant women with these conditions need to be evaluated for OSA. They also need to be suitably managed to ensure the healthy well-being of both the mother and the baby.

\section{Limitations}

Under reporting of information may be possible among participants with respect to snoring and other variables such as fatigability and daytime sleepiness. The cross-sectional design of this study is limited with regards to its ability to interpret temporality of the association. This could have been rectified had the same pregnant women been longitudinally followed up during the gestational period.

\section{Conflict of interest}

None declared.

\section{References:}

1. Hines J. Alaska Sleep Education Center. Snoring, sleep apnea and pregnancy. Available at: https://www.alaskasleep.com/ blog/snoring-sleep-apnea-and-pregnancy. [Last accessed at: 09.2019].

2. Izci-Balserak B, Zhu B, Gurubhagavatula I, et al. A screening algorithm for obstructive sleep apnea in pregnancy. Ann Am Thorac Soc. 2019; 16(10): 1286-1294, doi: 10.1513/annalsats.201902-131oc.

3. Bourjeily G, Danilack V, Bublitz M, et al. Obstructive sleep apnea in pregnancy is associated with adverse maternal outcomes: a national cohort. Sleep Med. 2017; 38: 50-57, doi: 10.1016/j.sleep.2017.06.035.

4. Champagne KA, Kimoff JR, Barriga PC, et al. Sleep disordered breathing in women of child bearing age and during pregnancy. Indian J Med Res. 2010; 131: 285-301.

5. Dominguez JE, Lockhart EM, Miskovic A, et al. Recognition of obstructive sleep apnea in pregnancy survey. Int J Obstet Anesth. 2016; 26: 85-87, doi: 10.1016/j.ijoa.2016.01.003.

6. Kapur V, Auckley D, Chowdhuri S, et al. Clinical Practice Guideline for Diagnostic Testing for Adult Obstructive Sleep Apnea: An American Academy of Sleep Medicine Clinical Practice Guideline. J Clin Sleep Med. 2017; 13(03): 479-504, doi: 10.5664/jcsm.6506.

7. Chung F, Subramanyam R, Liao P, et al. High STOP-BANG score indicates a high probability of obstructive sleep apnoea. Survey of Anesthesiology. 2012; 56(6): 312, doi: 10.1097/01. sa.0000422018.88507.a1.

8. Louis J, Pien GW. Obstructive sleep apnea in pregnancy. Available at: https://www.uptodate.com/contents/obstructive-sleep-apnea-in-pregnancy. [Last accessed at: 09.2019].

9. Tantrakul V, Sirijanchune P, Panburana P, et al. Screening of obstructive sleep apnea during pregnancy: differences in predictive values of questionnaires across trimesters. J Clin Sleep Med. 2015; 11(02): 157-163, doi: 10.5664/jcsm.4464.

10. Lockhart E, Abdallah AB, Tuuli M, et al. Obstructive sleep apnea in pregnancy. Obstet Gynecol. . 2015; 126(1): 93-102, doi: 10.1097/aog.0000000000000848.

11. Sarberg M, Svanborg E, Wiréhn AB, et al. Snoring during pregnancy and its relation to sleepiness and pregnancy outcome - a prospective study. BMC Pregnancy and Childbirth. 2014; 14(1), doi: 10.1186/1471-2393-14-15.

12. Puapornpong P, Neruntarat C, Manolerdthewan W. The prevalence of snoring in Thai pregnant women. J Med Assoc Thai. 2010; 93(Suppl 2): S102-105. 
13. Facco F, Kramer J, Ho K, et al. Sleep disturbances in pregnancy. Obstet Gynecol. . 2010; 115(1): 77-83, doi: 10.1097/ aog.0b013e3181c4f8ec.

14. Ismail M, Kumar R, Masood T, et al. Prevalence of obstructive sleep apnea in pregnancy: A hospital based study. Global Journal of Medicine and Public Health. 2015; 4: 1-5.

15. Lintott NC, Zyl DGV, Burke JL. Obstructive sleep apnoea in pregnancy and its association with pre-eclampsia. Southern African Journal of Anaesthesia and Analgesia. 2016; 23(1): 6-10, doi: 10.1080/22201181.2016.1251052.

16. Tantrakul V, Numthavaj P, Guilleminault C, et al. Performance of screening questionnaires for obstructive sleep apnea during pregnancy: A systematic review and meta-analysis. Sleep Med Rev. . 2017; 36: 96-106, doi: 10.1016/j.smrv.2016.11.003.

17. Izquierdo $\mathrm{F}$, Izquierdo $\mathrm{L}$, Blue $\mathrm{N}$, et al. Screening for obstructive sleep apnea during pregnancy in rural New Mexico [35H]. Obstetrics \& Gynecology. 2018; 131, doi: 10.1097/01. aog.0000533424.40945.8b.

18. Pien G, Pack A, Jackson N, et al. Risk factors for sleep-disordered breathing in pregnancy. Thorax. 2013; 69(4): 371-377, doi: 10.1136/thoraxjnl-2012-202718.

19. Fung A, Wilson D, Lappas M, et al. Effects of maternal obstructive sleep apnoea on fetal growth: a prospective cohort study. PLoS ONE. 2013; 8(7): e68057, doi: 10.1371/journal.pone.0068057.

20. Skoczylas M, Lęgowik A, Krawczyk P, et al. Risk assessment of obstructive sleep apnea in third trimester of pregnancy. Ginekologia i Poloznictwo. 2015; 35: 43-52.

21. Venkata C, Venkateshiah SB. Sleep-Disordered breathing during pregnancy. Am Board Fam Med. . 2009; 22(2): 158-168, doi: 10.3122/jabfm.2009.02.080057.
22. Dominguez J, Krystal A, Habib A. Obstructive sleep apnea in pregnant women. Anesth Analg. . 2018; 127(5): 1167-1177, doi: 10.1213/ane.0000000000003335.

23. Rice J, Larrabure-Torrealva G, Fernandez M, et al. High risk for obstructive sleep apnea and other sleep disorders among overweight and obese pregnant women. BMC Pregnancy and Childbirth. 2015; 15(1), doi: 10.1186/s12884-015-0633-x.

24. Li L, Zhao K, Hua J, et al. Association between sleep-disordered breathing during pregnancy and maternal and fetal outcomes: an updated systematic review and meta-analysis. Frontiers in Neurology. 2018; 9, doi: 10.3389/fneur.2018.00091.

25. Bourjeily G, Ankner G, Mohsenin V. Sleep-disordered breathing in pregnancy. Clinics in Chest Medicine. 2011; 32(1): 175189, doi: 10.1016/j.ccm.2010.11.003.

26. O'Keeffe M, St-Onge MP. Sleep duration and disorders in pregnancy: implications for glucose metabolism and pregnancy outcomes. International Journal of Obesity. 2012; 37(6): 765770, doi: 10.1038/ijo.2012.142.

27. Tasali E, Leproult R, Ehrmann DA, et al. Slow-wave sleep and the risk of type 2 diabetes in humans. Proc Natl Acad Sci USA. 2008; 105(3): 1044-1049, doi: 10.1073/pnas.0706446105.

28. Hermans M, Ahn S, Mahadeb Y, et al. Sleep apnoea syndrome and 10-year cardiovascular risk in females with type 2 diabetes: relationship with insulin secretion and insulin resistance. Diabetes Metab Res Rev. . 2013; 29(3): 227-234, doi: 10.1002/ dmrr.2387.

29. Guilleminault C, Kreutzer M, Chang J. Pregnancy, sleep disordered breathing and treatment with nasal continuous positive airway pressure. Sleep Medicine. 2004; 5(1): 43-51, doi: 10.1016/j.sleep.2003.07.001. 